\title{
MỨC Độ HÀI LÒNG VÀ NHU CẦU CỦA NGƯờI LAO ĐỘNG TAII CO' SỞ Y TẾ TƯ NHÂN CHƯA THÀNH LÂPP TỔ CHỨC CÔNG ĐOÀN
}

\section{Phạm Thanh Bình ${ }^{1}$, Hoàng Thị Mỹ Hạnh ${ }^{2}$, Nguyễn Thanh Tùng ${ }^{3}$, Nguyễn Đức Hữu ${ }^{4}$, Trần Thị Thu Hiền ${ }^{1}$, \\ relatively satisfied with the implementation of some policies at the unit. The need to be represented to protect the legitimate rights and interests of workers in small and medium-sized private health facilities (general/speciality clinics) in conjunction with the need to join trade unions is very high.}

\section{TÓM TẮT}

Mục tiêu: Mô tả mức độ hài lòng về các chế độ chính sách và nhu câu được tham gia tổ chức công đoàn và được bảo vệ các quyền và lợi ích hợp pháp của nqười lao động tai các cơ sở y tế tư nhẩn chưa thành lập tổ chức công đoàn. Phương pháp: Nghiên cứu mồ tả cắt ngang, thu thập thông tin định lượng qua phiếu hỏi tự điền với 299 người lao động và thảo luân nhóm người lao động ở một số cơ sở y tế tại Hà Nội, Hồ Chí Minh và Đà Năng. Kết quả: Điêm hài lòng bình quân với việc thực hiện các chính sách tại đớn vị là $>7 / 10$ điểm. Nhu câu được đại diện bảo vệ 15 quyền và lợi ích hợp giao động 7,2-8,2/10 điểm. 75\% người lao động có nhu cầu tham gia tổ chức công đoàn Kết luận: Nhìn chung người lao động khá hài lòng với việc thực hiện một số chính sách tại đơn vị. Nhu câuu được đại diện bảo vệ quyền và lợi ích chính đáng của người lao động tai các cơ sở y tế tư nhân quy mô vừa và nhỏ (các phòng khám đa khoa/chuyên khoa) cũng như' nhu câu tham gia công đoàn rất cao rất cao.

Tư khóa: cơ sở y tế tư nhân, phòng khám, chưa thành lập tổ chức công đoàn, mức độ hài lòng, nhu câuu, người lao động.

\section{SUMMARY \\ EMPLOYEES' DEMANDS AND LEVELS OF SATISFACTION AT PRIVATE HEALTH FACILITIES WITH UNESTABLISHED UNIONS}

Objective: Describe the level of satisfaction with policies and the needs to join trade unions for the protection of legitimate rights and interests of workers at private health facilities without established trade unions. Method: A cross-sectional descriptive study, quantitative information collection through selfcompleted questionnaires from 299 employees and group discussions with workers in several health facilities in Hanoi, Ho Chi Minh and Da Nang. Result: The average satisfaction score with the implementation of policies at the unit is $>7 / 10$ points. The demand for protection of 15 rights and interests by union representatives fluctuates between 7.2$8.2 / 10$ points. $75 \%$ of employees want to join trade unions. Conclusion: In general, employees are

${ }^{1}$ Công đoàn Y tế Việt Nam

${ }^{2}$ Nghiên cứu viên Viện Chiến lược và Chính sách Y tế ${ }^{3}$ Trường Đai hoc Công đoàn

${ }^{4}$ Nghiên cứu khoa học Viện Công nhân và Công đoàn Chiu trách nhiệm chính: Pham Thanh Bình ${ }^{1}$

Email: thanhbinhpham123456@gmail.com

Ngày nhận bài: 2.3.2021

Ngày phản biên khoa học: 23.4.2021

Ngày duyệt bài: 5.5.2021
Keywords: private medical facility, clinic, unestablished trade union, level of satisfaction, demand, employees.

\section{I. Đă̆T VẤN ĐỀ}

Sau hơn 30 năm Đổi mới, hệ thống y tế tư nhân ở nước ta đã nhanh chóng phát triển, tham gia cung cấp dịch vụ y tế, góp phân tăng sự lựa chọn, đáp ứng nhu câu chăm sóc sức khỏe của người dân. Đến nay, phát triển cơ sở khám, chữa bệnh là lĩnh vực y tế thu hút được khối tư nhân đầu tư nhiều nhất. Đến cuối năm 2018, cả nước có hơn 240 bệnh viện, 3.5000 phòng khám đa khoa chuyên khoa tư nhân ${ }^{1}$. Hiện chưa có số liệu thống kê chính xác về số lượng người lao động đang làm việc tại các cơ sở y tế tư nhân nhưng lực lượng này đang ngày một gia tăng nhanh chóng, là nguồn nhân lực y tế quan trọng của đất nước (Bộ Y tế Việt Nam 2015. Báo cáo chung tổng quan ngàn y tế năm 2015. Tăng cường y tế cơ sở hướng tới bao phủ chăm sóc sức khỏe toàn dân. Tuy nhiên, do đặc thù đa số các cơ sở y tế tư nhân cung cấp dịch vụ KCB và dược ở nước ta có quy mô nhỏ và siêu nhỏ, phần lớn các cơ sở này chưa thành lập tổ chức công đoàn cơ sở. Vì vậy, chưa có cơ chế để nắm bắt thông tin về thực trang công tác đảm bảo quyền và lợi ích hợp pháp của người lao động trong lĩnh vực này.

Theo bộ luật Lao động năm 2019, từ ngày 1/1/2021, người lao động được quyền thành lập, gia nhập và tham gia hoạt động của tổ chức đại diện người lao động độc lập với hệ thống công đoàn cơ sở thuộc Tổng liên đoàn lao động Việt Nam. Trong thời gian tới, để tiếp tục thu hút, tập hợp người lao động ở khu vực y tế tư nhân tham gia tổ chức công đoàn Việt Nam, việc nắm bắt được được mong muốn và nhu câu được bảo vê quyền và lợi ích hợp pháp của người lao động trong các quan hệ lao động ở khu vực này là hết sức cân thiết.

Trong bối cảnh đó, Công đoàn Ngành $Y$ tế Viêt Nam đã đề xuất và được giao chủ trì triển khai nghiên cứu Đổi mới phương thức tập hợp 
người lao động tham gia tổ chức Công đoàn giai đoạn thực hiện các hiệp định thương mại thế hệ mới CPTPP, EVFTA. Trong phạm vi bài báo này, chúng tôi mô tả mức độ hài lòng về các chế độ chính sách và nhu cầu được bảo vệ các quyền và lợi ích hợp pháp của người lao động tại các cơ sở y tế tư nhân chưa thành lập tổ chức công đoàn, sử dụng một phần số liệu từ nghiên cứu nêu trên.

\section{II. ĐỐI TƯỢNG VÀ PHƯƠNG PHÁP NGHIÊN CỨU}

1. Đối tượng và địa bàn nghiên cứu: Đối tượng nghiên cứu là người lao động đang làm việc tại các phòng khám đa khoa/chuyên khoa và doanh nghiêp dược tư nhân ở 3 địa phương thuộc nhóm tỉnh/thành phố có tốc độ phát triển y tể tư nhân lớn của cả nước, đại diện 3 miền Bắc, Trung, Nam, lần lượt gồm TP.Hà Nội, TP Đà Nẵng và TP.Hồ Chí Minh.

2. Cỡ mẫu và phương pháp chọn mẫu: Cõ̃ mẫu người lao động cần khảo sát ( $\mathrm{n}$ ) được tính theo công thức tính cõ̃ mẫu một tỷ lệ

$$
n=Z_{(1-\alpha / 2)}^{2} \cdot \frac{p(1-p)}{d^{2}}
$$

Trong đó: z: Hệ số tin cậy; với độ tin cậy $95 \%$ thì giá trị của $z=1,96$; $\mathrm{p}$ : tỷ lệ người lao động có nhu cầu tham gia công đoàn/tổ chức đại diện cho người lao động. Do chưa có nghiên cứu về nhu cầu tham gia công đoàn của người lao động tại các cơ sở y tế tư nhân nên giả định tỷ lệ này lớn hơn $10 \%$, và ở mức $50 \%(p=0,5)$ để có cỡ mẫu lớn nhất; $\mathrm{q}=1-\mathrm{p}=0,5$; $\mathrm{d}$ : sai số chấp nhận $=0,07$. Với $\mathrm{DE}=1.5$ và tỷ lệ từ chối/phiếu không hoàn thành ước tính $7 \%$, áp dụng công thức trên, số lượng người lao động cần khảo sát là 315 người, tương ứng 105 người tại mỗi tỉnh/thành phố. 30 phòng khám tư nhân và 1 doanh nghiệp chưa thành lập công đoàn có quy mô người lao động tương đối đông được chọn tham gia khảo sát này. Tại mỗi cơ sở, từy theo quy mô người lao động, 5-15 người đã được chọn ngẫu nhiên mời tham gia nghiên cúu.

3. Phương pháp thu thập thông tin: Đối với phiếu hỏi định lượng, người lao động tự đọc và điền phiếu. Nhóm 299 người lao động đã hoàn thành phiếu khảo sát.

Mỗi nhóm gồm 2-3 nghiên cứu viên đã trực tiếp tiến hành 5 cuộc thảo luận nhóm với người lao động tại 5 phòng khám. Nội dung thảo luận được ghi chép/ đánh máy đầy đủ.

4. Cách thức đo lường mức độ hài lòng và nhu câu và thực trạng đảm bảo quyên và lợi ích hợp pháp của người lao động. Người lao động tự chấm điểm mức độ hài lòng của bản thân về thực trạng triển khai 14 nội dung liên quan đến chính sách cho người lao động của cơ sở đang công tác và tự đánh giá nhu cầu về 15 nội dung liên quan đến quyền, lợi ích của bản thân theo thang điểm 1-10 trong đó 10 tương đương với rất hài lòng hoặc có nhu cầu rất cao, và 1 tương ứng với rất không hài lòng hoặc không có nhu cầu. Ngoài ra, bộ câu hỏi bao gồm một số các câu hỏi về thực trạng đảm bảo quyền và lợi ích hợp pháp và nhu cầu thành lập tổ chức đại diện cho người lao động được thiết kế dưới dạng câu hỏi với phương án trả lời "có/không".

5. Phương pháp xử lý thông tin. Phiếu khảo sát định lượng được làm sạch, nhập liệu và phân tích bằng phần mềm SPSS. Mức độ hài lòng và mức nhu cầu được báo cáo bằng điểm trung bình trên thang điểm 10 . Thực trạng triển khai và nhu cầu thành lập tổ chức đại diện cho người lao động được báo cáo bằng tỷ lệ phần trăm người lao động trả lời có cho từng câu hỏi. Các nội dung thảo luận nhóm được phân tích theo nhóm chủ đề.

\section{KẾT QUẢ NGHIÊN CỨU}

1. Thông tin chung về người trả lời \begin{tabular}{|l|l|l|}
\hline Đặc điếm của người trả lời & $(\%) \mathbf{N}=299$ \\
\hline
\end{tabular}

\begin{tabular}{|c|c|}
\hline \multicolumn{2}{|c|}{ Giới tính } \\
\hline Nữ & 69,2 \\
\hline Nam & 30,8 \\
\hline \multicolumn{2}{|c|}{ Loại CSYT } \\
\hline Phòng khám & 91,0 \\
\hline Doanh nghiệp Dược & 9,0 \\
\hline \multicolumn{2}{|c|}{ Vị trí làm việc hiện tại } \\
\hline Hành chính & 29,1 \\
\hline Chuyên môn & 64,2 \\
\hline Quản lý & 3,3 \\
\hline \multicolumn{2}{|c|}{ Nghề nghiệp } \\
\hline Bác sỹ & 9,7 \\
\hline Điều dưỡng & 25,8 \\
\hline Kỹ thuật viênn & 22,1 \\
\hline Dược sỹ & 16,7 \\
\hline Nữ hộ sinh & 1,7 \\
\hline Nhân viên hành chính & 18,7 \\
\hline Khác & 5,4 \\
\hline \multicolumn{2}{|c|}{ Hình thức lao động* } \\
\hline Toàn thời gian & 90,3 \\
\hline Bán thời gian & 6,5 \\
\hline Theo vụ việc & 3,2 \\
\hline \multicolumn{2}{|c|}{ Thâm niền công tác tại đơn vị } \\
\hline < 1 năm & 13,4 \\
\hline $1-<3$ năm & 26,4 \\
\hline $3-<5$ năm & 22,7 \\
\hline$>=5$ năm & 37,5 \\
\hline Quy mô lao động & \\
\hline
\end{tabular}




\begin{tabular}{|c|c|}
\hline$>=25$ người & 22,7 \\
\hline$<25$ người & 77,3 \\
\hline Địa bàn & \\
\hline Hà Nội & 33,8 \\
\hline Đà Năng & 33,4 \\
\hline TP Hồ Chí Minh & 32,8 \\
\hline
\end{tabular}

$* \mathbf{N}=\mathbf{2 7 8}$

2. Mức độ hài lòng của người lao động về các chế độ chính sách và điêuu kiên làm việc đối với người lao động. Điểm sổ trung bình chung về mức độ hài lòng của người lao động về các chế độ chính sách cho người lao động trong cơ sở y tế tư nhân được khảo sát đạt 7.27/10 điểm. Trong 14 nội dung, 4 nội dung người lao động chưa hài lòng nhất là chính sách thi đua khen thưởng, thông tin, phản hồi ý kiến với người sử dụng lao động tố chức hoạt động vui chơi, giải trí động viên tinh thần người lao động và tiên lương hiện tại (< 7/10 điểm). Chính sách tiền lương, chất lượng bữa ăn ca và các chế độ phúc lợi thuộc nhóm nội dung có điểm hài lòng thấp thứ hai (7-7,05/10 điểm). Người lao động hài lòng nhất (8.07/10 điểm) do được tham gia đóng góp ý kiến vào các hoạt động của đơn vị, tiếp đến là đơn vị có cơ chế khuyến khích tham gia cải tiến, và chính sách đào tạo phát triển, đề bạt và thăng chức (7,8/10 điểm) (Bảng 1)

Bảng 2: Điểm số trung binh mức độ hài lòng về các chế độ chính sách của người lao động tai cơ sở y tế tư nhân chưa thành lập tổ chức công đoàn*

\begin{tabular}{|c|c|}
\hline Tiêu chí & $\begin{array}{l}\text { Điểm hài } \\
\text { lòng } \\
\text { trung } \\
\text { bình*/10 }\end{array}$ \\
\hline $\begin{array}{l}\text { Tổ chức các hoạt động vui chơi, } \\
\text { giải trí nhân dịp kỷ niệm hoặc các } \\
\text { kỳ nghỉ của đớn vị }\end{array}$ & 6.78 \\
\hline Chính sách thi đua khen thưởng & 6.75 \\
\hline $\begin{array}{l}\text { Việc thông tin, phản hôi ý kiến } \\
\text { của bản thân với NSDLĐ; }\end{array}$ & 6.79 \\
\hline Vấn đề khám sức khỏe định kỳ & 7.34 \\
\hline Sự ổn định của công việc & 7.31 \\
\hline $\begin{array}{c}\text { Điều kiện làm việc (môi trường, } \\
\text { công cụ làm việc, ...) }\end{array}$ & 7.37 \\
\hline $\begin{array}{l}\text { Các chế độ phúc lợi do đơn vị } \\
\text { cung cấp; }\end{array}$ & 7.05 \\
\hline $\begin{array}{l}\text { Chính sách tiền lương của đơn vị } \\
\text { (nâng lương, cách tính lương, } \\
\text { thang, bảng lương) }\end{array}$ & 7.00 \\
\hline Tiên lương đang nhận được & 6.98 \\
\hline Chất lượng bữa ăn ca & 7.00 \\
\hline Chính sách đào tạo và phát triển; & 7.83 \\
\hline
\end{tabular}

\begin{tabular}{|c|c|}
\hline $\begin{array}{c}\text { Tham gia ý kiến vào các hoạt } \\
\text { động của cơ sở }\end{array}$ & 8.07 \\
\hline $\begin{array}{c}\text { Cơ chễ khuyến khích NLD tham } \\
\text { gia vào quá trình cải tiến trong } \\
\text { đơn vị }\end{array}$ & 7.80 \\
\hline $\begin{array}{c}\text { Chính sách đề bạt, thăng chức } \\
\text { của đơn vị; }\end{array}$ & 7.79 \\
\hline Tổng cộng trung bình & $\mathbf{7 . 2 7}$ \\
\hline
\end{tabular}

*Điểm trung bình được tính trên tổng số người có chấm điểm/trả lời. Tỷ lệ missing ở một số nội dung < $10 \%$ trên tổng số 299 người trả lời

Kết quả thảo luận nhóm cho thấy do thiếu vắng tổ chức đại diện cho người lao động nên người lao động nếu làm việc tại các đơn vị có quy mô nhỏ phải trực tiếp thông tin, phản hồi ý kiến của bản thân đến NSDLĐ. Tại các đơn vị có quy mô lớn hơn có cơ cấu phòng ban chức năng thì phòng nhân sự sẽ có vai trò giải đáp mọi thắc mắc liên quan đến chế độ chính sách của NLĐ. Điều này có thể đã hạn chế tính kịp thời và hiệu quả của việc trao đổi thông tin ý kiến giữa NLĐ và NSDLĐ, dấn đến việc NLĐ chưa hài lòng nêu trên.

Về việc chăm lo đời sống vật chất, tinh thần, việc giải đáp thắc mắc và thực hiện chế độ chính sách nói chung cho người lao động, đa số (hơn $50 \%$ ) người lao động cho rằng lãnh đạo đơn vị chưa quan tâm đến các vấn đề này.

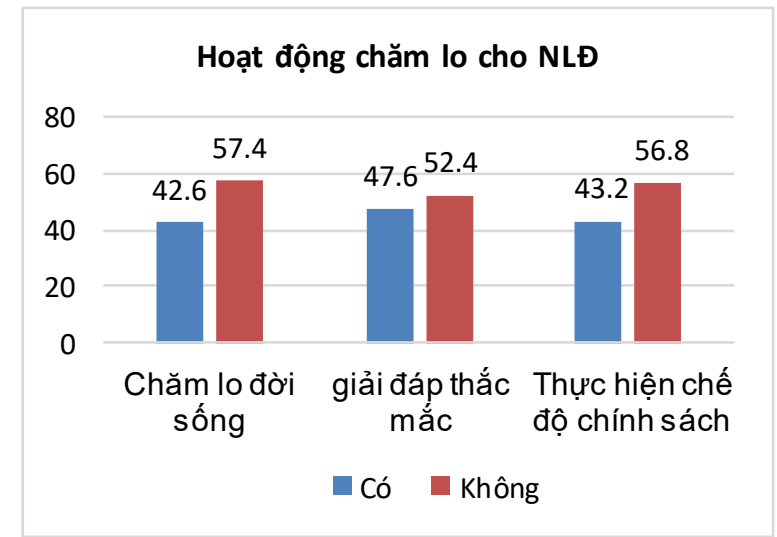

\section{Biểu 1: Thức hiên việc chăm lo cho NLĐ trong đớn vị chưa có CĐCS}

Có tình trạng bất bình trong tâm tư của những nhân viên y tế tại các cơ sở này về công tác chăm lo sức khỏe, dự phòng phơi nhiểm bênh.

*Có một nghịch lý là trong khi chúng tôi đi khám sức khỏe cho cộng đồng thì bản thân chính chúng tôi lại không được bảo vệ thông qua khám sức khỏe định kỳ. Doanh nghiệp cho rằng đơn vị có sẵn nguiồn lực nên có thể hỗ trợ nhân viên y tế bất cứ lúc nào. Điều này ít nhiều gây cho chúng tôi tâm lý bất an vì công tác phòng 
bệnh thông qua phát hiện sớm không được doanh nghiệp quan tâm.

Nũ̃, 51 tuổi, Hà Nội, TLN NLĐ

**Chúng em trong hợp đồng lao động cũng có nói là được khám sức khỏe, nhưng từ lúc em làm việc ở đây hơn 2 năm mà chưa thây có đợt khám bệnh nào dành cho nhân viên. Chỉ có ai đau bệnh mới được hưởng việc khám nhưng chi trả cũng không rẻ hơn bao nhiêu so với người bệnh khác -Nũ̃, 26 tuổi, TPHCM, TLN NLĐ

3. Nhu câu đại diện bảo vệ quyên, Iợi ích của người lao động trong các cơ sở y tế ngoài công lập chưa có tổ chức công đoàn.

Bảng 3: Mức độ nhu cầu của người lao động về một số nội dung liên quan đến quyền, lợi ích của người lao động

\begin{tabular}{|c|c|}
\hline Các nội dung & $\begin{array}{c}\text { Điểm mức } \\
\text { độ nhu câu } \\
\text { trung } \\
\text { bình } / 10\end{array}$ \\
\hline $\begin{array}{c}\text { Nhu cầu được hướng dần, tư vấn khi giao kết, thực hiện Hợp đồng lao động, hợp } \\
\text { đồng làm việc }\end{array}$ & 8.22 \\
\hline $\begin{array}{c}\text { Nhu cầu được đảm bảo các điều kiện về bảo hộ lao động và an toàn vệ sinh lao } \\
\text { động }\end{array}$ & 8.08 \\
\hline $\begin{array}{c}\text { Nhu cầu được đại diện thương lượng, ký kết và giám sát việc thực hiện thỏa ước } \\
\text { lao động tập thể }\end{array}$ & 7.85 \\
\hline $\begin{array}{l}\text { Nhu cầu được đại diện tham gia xây dựng và giám sát việc thực hiện thang } \\
\text { lương, bảng lương, định mức lao động, quy chế trả lương, quy chế thưởng, nội } \\
\text { LĐ }\end{array}$ & 7.84 \\
\hline $\begin{array}{c}\text { Nhu cầu được đại diện đối thoại với NSDLĐ để giải quyết các vấn đề liên quan } \\
\text { đến quyền lợi và nghĩa vụ của NLĐ }\end{array}$ & 7.81 \\
\hline Nhu cầu được tư vấn pháp luật & 7.75 \\
\hline $\begin{array}{c}\text { Nhu câu được đại diện để tham gia với cơ quan, tổ chức, cá nhân có thẩm quyền } \\
\text { giải quyết tranh chấp lao động }\end{array}$ & 7.65 \\
\hline $\begin{array}{l}\text { Nhu câu được đại diện để kiến nghị với tố chức, cơ quan nhà nước có thẩm quyền } \\
\text { xem xét, giải quyết khi quyền, lợi ích của tập thể NLĐ hoặc của NLĐ bị xâm phạm }\end{array}$ & 7.67 \\
\hline Nhu cầu được đại diện để khởi kiện tại Tòa án khi quyền, lợi ích bị xâm phạm & 7.75 \\
\hline $\begin{array}{c}\text { Nhu câu được đại diện tham gia tố tụng các vụ án lao động, hành chính, phá sản } \\
\text { để bảo vệ quyền, lợi ích }\end{array}$ & 7.62 \\
\hline $\begin{array}{c}\text { Nhu cầu được đại diện để tham gia với đơn vị trong việc xây dựng chương trình, } \\
\text { kế hoạch, chính sách liên quan đến NLĐ }\end{array}$ & 7.69 \\
\hline Nhu cầu được tham gia thanh tra, kiểm tra, giám sát hoạt động đơn vị & 7.60 \\
\hline Nhu cầu được tuyên truyền, vận động, giáo dục & 7.76 \\
\hline Nhu cầu được giải quyết tranh chấp LĐ & 7.68 \\
\hline Nhu câu được tham gia các hoạt động phong trào & 7.78 \\
\hline
\end{tabular}

*Điểm trung bình được tính trên tổng số người có chấm điểm/trả lời. Tỷ lệ missing ở một số nội dung < $8 \%$ trên tổng số 299 người trả lời

4. Nhu câu của người lao động về tham gia công đoàn trong các cơ sở chưa có CĐCS

Mặc dù chưa có tổ chức đại diện về hoạt động công đoàn tại đơn vị, 87,2 người trả lời đã
Người lao động có nhu cầu cao về tất cả 15 nội dung liên quan đến bảo vệ quyền, lợi ích, trong đó nhu cầu cao nhất là được hướng dẫn, tư vấn khi giao kết hợp đồng lao động, hợp đồng làm việc (8,22/10 điểm); nhu cầu được bảo đảm các điều kiện về bảo hộ lao động và an toàn vệ sinh lao động $(8,08 / 10$ điểm). Nhóm vấn đề có nhu cầu cao tiếp theo là được tham gia thanh tra, kiểm tra, giám sát hoạt động của đơn vị về thực hiện thỏa ước lao động tập thể và các vấn đề về tiền lương, được tư vấn pháp luật $(7,8$ điểm/10)...(Bảng 3) 


\section{BÀN LUẬN}

Nghiên cứu này tổng hợp ý kiến của người lao động từ 30 cơ sở y tế tư nhân, chủ yếu là phòng khám đa khoa và chuyên khoa tại 3 thành phố có tốc độ phát triển các cơ sở y tế tư nhân lớn của cả nước. Đây là nghiên cứu đâuu tiên được xuất bản cung cấp bằng chứng về mức độ nhu cầu được bảo vệ quyền và lợi ích chính đáng cũng như nhu cầu tham gia công đoàn của người lao động tại các cơ sở y tế chưa thành lập tổ chức công đoàn có quy mô nhỏ vốn là loại hình cơ sở KCB tư nhân phổ biến nhất ở nước ta.

Nghiên cứu cho thấy nhân viên y tế/người lao động đã thực sự quan tâm và có nhu cầu cao trong tất cả 15 nội dung liên quan đến quyền và lợi ích mà nếu không có tổ chức trung gian đại diện cho người lao động thì quan hệ lao động giữa cá nhân người lao động và chủ sử dụng lao động khó giải quyết được. Nhu cầu cao nhất hiện nay của người lao động là được hướng dẫn, tư vấn khi giao kết hợp đồng lao động, hợp đồng làm viêc, được tham gia thanh tra, kiểm tra, giám sát hoạt động của đơn vị về thực hiện thỏa ước lao động tập thể và các vấn đề về tiền lương và được tư vấn pháp luật. Đây là những gợi mở cho cồng đoàn Việt Nam trong công tác truyền thông, vận động thành lập công đoàn trong hệ thống phòng khám tư nhần cũng như nâng cao chất lượng các nội dung hoạt động trọng điểm để đáp ứng nhu cầu của người lao động thuộc khu vực y tế tư nhân trong giai đoạn tới.

Nhu câuu được bảo đảm các điểu kiện về bảo hộ lao động và an toàn vê sinh lao động ở mức cao hiện nay của NVYT tại các đơn vị được khảo sát có thể được giải thích bởi thực tế nguy cơ phơi nhiễm với các yếu tố nguy với sức khỏe tai làm việc ngày càng tăng do các dịch bệnh mới nổi như Covid-19. Kết quả nghiên cứu của đề tài "Đổi mới phương thức tập hợp người lao động tham gia tổ chức Công đoàn giai đoạn thực hiện các hiệp định thương mại thế hệ mới CPTPP, EVFT cũng cho thấy so với các đơn vị chưa thành lập công đoàn, người lao động tại các cơ sở y tế tư nhân đã thành lập công đoàn hài lòng hơn với các điều kiện về bảo hộ lao động và an toàn vệ sinh lao động tại đơn vị (Phạm Thi Thanh Bình và cộng sự 2021). Có thể các tổ chức công đoàn ở khu vực tư nhân đã phát huy được vai trò của mình trong công tác chăm lo, bảo vệ sức khỏe đoàn viên.

Theo kêt quả nghiên cứu, 71,5\% người lao động đồng thuận chức năng quan trọng nhất của tổ chức công đoàn là bảo vệ quyền và lợi ích hợp pháp cho người lao động. Tuy nhiên, chỉ
$53,9 \%$ số người biết về quyền thành lập tổ chức công đoàn. Đây là một khối lượng công việc lớn về công tác tuyên truyền trong hệ thống công đoàn cần triển khai trong thời gian tới, không chỉ tuyên truyền vai trò của tổ chức công đoàn, mà phải hướng dẫn cụ thể người lao động muốn tham gia công đoàn tại khu vực ngoài công lập phải thực hiện những bước như thế nào.

Việc hơn $75,6 \%$ người lao động có nhu cầu tham gia tổ chức công đoàn là một tín hiệu rất đáng mừng nhưng cũng là một thách thức rất lớn cho công đoàn Việt Nam trong việc thu hút NLĐ tham gia tổ chức của mình trong thời gian tới. Nếu các Tổ chức công đoàn Việt Nam cơ sở hiện nay không thuyết phục, chứng minh được tính ưu việt của mình trong bảo vệ quyền lợi, lợi ích của NLĐ khi gia nhập công đoàn Việt Nam thì NLĐ sẽ tìm đến tổ chức đại diện người lao động khác đại diện cho quyền, lợi ích của họ.

\section{KẾT LUÂN}

Nhóm các vấn đề mà người lao động/NVYT tại các cơ sở y tế tư nhân chưa hoàn toàn hài lòng về đơn vị mình bao gồm chính sách tiền lương, chế độ phúc lợi, chăm lo đời sống tinh thần và khuyến khích động viên khen thưởng cũng như cơ chế thông tin, phản hồi ý kiến với người sử dụng lao động. Nhu cầu được đại diện bảo vệ quyền và lợi ích chính đáng của người lao động tại các cơ sở y tế tư nhân quy mô vừa và nhỏ là $71,5 \%$ và $75,6 \%$ người lao động được điều tra có nhu cầu tham gia công đoàn.

\section{KIẾN NGH!}

Tổng liên đoàn cần có hướng dẫn cụ thể về thành lập công đoàn ghép đối với các công đoàn ngoài cồng lập có số lượng ít ở các phòng khám chuyên khoa và xây dựng kế hoạch tổng thể tuyên truyền đối tượng ngoài công tham gia tổ chức công đoàn từ nhận thức đến các bước triển khai thành lập các tổ chức công đoàn theo các hình thức phù hợp.

\section{TÀI LIÊU THAM KHẢO}

1. Lê Minh Sang, Ramesh Govindaraj, và Caryn Bredenkamp. Đối tác công tư y tế ở Việt Nam Vấn đề và lựa chọn. https://openknowledge. worldbank.org/ bitstream/handle/ 10986/33724/ 9781464815850.pdf? sequence $=4 \&$ isAllowed $=y$

2. Bộ Y tế Việt Nam 2015. Báo cáo chung tổng quain ngàn y tế năm 2015. Tăng cường y tể cơ sơ hướng tới bao phủ chăm sóc sức khỏe toan dân

3. Phạm Thanh Bình và cộng sự 2021. Báo cáo kết quả nghiên cứu Đổi mới phương thức tâp hợp người lao động tham gia tổ chức Cổng đoàn trong các cơ sở y tế ngoài công lập trong điêuu kiện Việt Nam thực hiện CPTPP, EVFTA" 